\title{
CHUZOS, LÁPICES Y MATRACAS. PROLETARIOS, POETAS Y PROMESANTES EN EL NORTE GRANDE DE CHILE ${ }^{1}$
}

\section{STICKS, PENCILS AND NOISEMAKERS. PROLETARIANS, POETS AND PROMISING PEOPLE IN THE LARGER NORTHERN ZONE OF CHILE}

\author{
Bernardo Guerrero Jiménez \\ Universidad Arturo Prat \\ bernardo.guerrero@gmail.com
}

\begin{abstract}
Resumen:
El proletariado del salitre en el Norte Grande de Chile produjo un fuerte y combativo movimiento obrero; uno de los primeros en América Latina. Desarrolló además una intensa actividad cultural, a través del teatro, y sobre todo escribió poesía obrera que quedó impresa en los periódicos. Pero también se organizó en bailes religiosos para asistir a la fiesta de La Tirana y San Lorenzo. Ambas actividades se realizaban fuera del tiempo rutinario del trabajo. La noche los albergó. Estudiamos esas relaciones en tanto actividades inscritas en horizontes diferentes y a veces complementarios. Un obrero ilustrado y un obrero peregrino que comparten un mismo trabajo.
\end{abstract}

Palabras clave: Trabajo, religiosidad popular, poesía obrera.

\begin{abstract}
:
The saltpetter working class in the North of Chile produced a strong and spirited laborer movement. One of the first ones in Latin America. Also it developed an intense cultural activity through the theater and, above all, it wrote working class poetry later printed on newspaper. They also organized themselves in religious dance groups to attend La Tirana and San Lorenzo festivities. Both activities were produced after labour routine time. The night sheltered them. We study these relationships in as much activity reports formed in different horizons and sometimes complementary. An enlighted working class man and a working class pilgrim who shared a similar job.
\end{abstract}

Key words: Job, popular religiosity, working class poetry.

Recibido: 29 de abril de 2021

Aceptado: 22 de junio de 2021

\footnotetext{
${ }^{1}$ Trabajo escrito en el marco del proyecto "Dinámicas identitarias en el Norte Grande de Chile: Nación, región y religiosidad popular", No 1141306 Fondecyt.
} 
Artículo. Bernardo Guerrero. "Chuzos, lápices y matracas, proletarios, poetas y promesantes en el norte grande de Chile"

\section{Palabras previas}

A fines del siglo XIX, Clodomiro Castro publica el poema "Las pampas salitreras" considerado como la primera poesía sobre esta actividad realizada en el desierto de Atacama. Está fechado el año 1896. Luego vendría la novela Historia de un esclavo de Mariano Martínez (1895) y Tarapacá de Osvaldo López y Nicanor Polo, publicado bajo el seudónimo de Juanito Zola² , editada el año 1903 y reeditada el 2003, en Iquique.

Sin embargo, en la prensa proletaria empieza a desarrollarse lo que se conoce como poesía obrera. Escrita por trabajadores, a menudo, con seudónimo, y como veremos más adelante, anticlerical y que posee algunos vasos comunicantes con los cantos religiosos marianos de la fiesta de La Tirana.

Es, en términos generales, una literatura no hegemónica. Lo anterior en el sentido que no es objeto de una crítica literaria, lo que ocurre con toda lo que cabe en la llamada "literatura popular". Carece de redes sociales y de capitales simbólicos, entre otros elementos (Sapiro, La sociología). Además, circula a través de circuitos acotados, y en el caso del Norte Grande, por una población que tiene altos niveles de analfabetismo, altas tasas de alcoholismo, entre otros problemas sociales (Salas, Comisión). No obstante, y pese a lo anterior, poseen instrumentos tecnológicos que le permite imprimir diarios, folletos, panfletos, etc. Muchas veces estas imprentas son destruidas por grupos asociados a la élite salitrera. El caso del Despertar de los Trabajadores es significativo, aunque en la novela Tarapacá ya aparecen narrados actos violentos en contra de la prensa obrera.

La sociedad del Norte Grande de Chile, al 1900, muestra, por parte de la clase dominante, asociada a la explotación del salitre, extranjeros europeos, sobre todo ingleses, franceses, alemanes, españoles, entre otros, un consumo cultural diversificado y sofisticado. Así, por ejemplo, el año 1866 visita Iquique la actriz y cantante Sara Bernhardt, cuya fama en Europa y en Estados Unidos es indiscutible (Sagan, Buenos). Su actuación en un teatro más bien humilde, motiva a que la élite salitrera construya el actual teatro Municipal que se inaugura el año 1899. El año 1911 visita la ciudad el futuro premio Nobel, Jacinto Benavente, dramaturgo. Y así, muchos ejemplos más. Los ateneos de la élite salitreras son

\footnotetext{
${ }^{2}$ En clara alusión al autor francés Emile Zolá. Lo que habla de cierta apropiación de este autor francés por parte de Osvaldo López, por su obra "Yo acuso" publicada el año 1898.
} 
replicados por los obreros. En la novela, las obras de Víctor Hugo, Marcel Proust, Emile Zola, son consumidas por quienes tienen acceso a estos bienes culturales.

Estas obras son objetos de análisis y de crítica por el canon ilustrado proveniente de Europa. La producción y circulación de estas obras se inscriben en lo que hoy se podría denominar industria cultural. La literatura obrera o salitrera como se denomine (Moretic, $E l$ Relato) va a carecer de estos elementos.

La élite salitrera, además, construye biblioteca y empieza en concordancia con el estado a levantar establecimientos educacionales. Los hay laicos como el Liceo de Hombres, como también metodistas como el Iquique English College ambos de fines del siglo XIX.

No obstante, la riqueza del mundo proletario del Norte Grande de Chile, es que se niega a ser consumidor pasivo de lo que le ofrece el mercado regional, mediado por el "buen" gusto de la élite salitrera. Y superan la resistencia y producen sus propias obras y espacios para exhibir sus producciones. No es sólo literatura, sino que también teatro (Bravo-Elizondo, Cultura). Todos ellos usados como "aparatos" para la conquista de una nueva sociedad. Parafraseando a Spivak (2011) son los subalternos, los que hablan, aunque en rigor, son los explotados, siguiendo la crítica que esta hace del marxismo. Los ateneos obreros son parte de la sociabilidad popular en la que se levantan bibliotecas, se presentan obras de teatro y se discuten temas de actualidad.

Conocemos la literatura obrera, sobre todo la poesía y novela, gracias al trabajo de historiadores, sociólogos, literatos que se han preocupados por darle visibilidad a estos discursos.

\section{Cultura popular en el Norte Grande}

La historiografía clásica siempre habló de la clase obrera y en consecuencia de la cultura obrera (Bravo-Elizondo, Cultura), para referirse a ese complejo, no siempre homogéneo, de prácticas socio-culturales, políticas, económicas y religiosas que se produjo en el Norte Grande de Chile, activado por la explotación del salitre. El concepto nos direcciona a las clásicas nociones de la baja cultura y la alta cultura (Burke, La cultura) o bien de aquellos productos producidos y consumidos por el pueblo. Para otros, el concepto de popular remite a una idea de contra hegemonía respecto a la elite que impone sus 
Artículo. Bernardo Guerrero. "Chuzos, lápices y matracas, proletarios, poetas y promesantes en el norte grande de Chile"

consideraciones acerca de lo que es correcto o no, bello o feo, etc. Certeau (2009), repasa el uso del concepto de popular, a través de la tradición oral, el folclore, la vida provinciana, entre otros. En el Norte Grande se usó, por los propios proletarios, la expresión clase obrera para así distinguirse de la burguesía. Tanto los obreros, poetas y peregrinos, pertenecían a la clase obrera y en su condición eran anti-burgueses y anti-clericales. Pero también se llamaron pampinos. Mientras que los dueños de las oficinas eran los salitreros. Estas dos denominaciones eran las dominantes, pero entre ellas había una serie de otros estratos sociales con sus propias prácticas culturales: indígenas, niños, jóvenes, chinos, y sobre todo mujeres que eran invisibles para el discurso tanto de la élite como de la clase obrera.

La cultura obrera del Norte Grande, como veremos más adelante, es la combinación, recreación e innovación de las diferentes prácticas culturales que allí y en ese tiempo, se mezclaron. Este párrafo de Mario Bahamonde lo certifica:

El nortino es hijo de la aventura y no de la tradición. Pero es un hijo legítimo, con todos los honores del aventurero, desde los remotos abuelos españoles hasta los más recientes transeúntes del destino zonal (Pampinos 1).

Este territorio fue el lugar de encuentro de varias trayectorias que, tanto en las oficinas salitreras como en los puertos, se encontraron. El pueblo, la otra noción en boga, estaba compuesto por campesinos venidos del centro y sur de Chile, por soldados que habían luchado tanto en la Guerra del Pacífico como en la revolución del 1891, por indígenas venidos del Oriente, del altiplano y de valles de Tarapacá y Antofagasta, estructuraron lo que hoy podría denominarse cultura popular.

La clase obrera encontró en sus organizaciones de base tanto políticas como culturales, la forma de denunciar la explotación de que era objeto. La literatura fue una de ella, y en particular la poesía obrera, uno de sus sellos distintivos. Pero también halló en los deportes como el fútbol y el boxeo otra forma de estar juntos ${ }^{3}$. Lo mismo aconteció con los bailes religiosos que se organizaban para ir a la fiesta de La Tirana, San Lorenzo y a otras festividades locales del Norte Grande, de cada pueblo de los valles y altiplano. Estas dos

\footnotetext{
${ }^{3}$ En la poesía obrera analizada hay un solo poema dedicado al fútbol. Es un acróstico al equipo de fútbol de Cala-Cala: "A la educación física propendemos/ la educación de nuestros consocios moral/ Así a la cúspide llegaremos/ Con ánimo sereno sin igual" (González, Illanes y Moulián 431).
} 
últimas actividades, el deporte y la religiosidad popular, carecían de la discursividad política expresa que por ejemplo tenía la poesía obrera. Pero como veremos más adelante, no eran contradictorios entre sí.

Esta cultura popular del Norte Grande no era homogénea. Diversas tradiciones cohabitaron entre sí. El obrero con conciencia de clase era un hombre que aspiraba a realizar la idea de un ser racional e ilustrado, cuyo modelo ejemplar está en la novela Tarapacá de Juanito Zola, en la que su personaje Juan Pérez, encarna esos ideales (Guerrero, Tarapacá). Sin embargo, esas piezas tienen una fuerte resonancia con la poesía popular venida del campo chileno, y que se articulaba en torno a temas como la religión, las disputas entre el diablo y los peones, etc. Juan Rafael Allende, al decir de Salinas "profesaba un rabioso anticlericalismo" (Salinas et al. 71). Por otro lado, en los bailes religiosos se congregaban quienes profesaban un marianismo, más bien ligado a lo que Eliade (1968) plantea como un cristianismo cósmico, que traen los campesinos del sur de Chile y que cultivan los andinos de esta parte de la nación. Una religión que cruza la vida cotidiana de sus habitantes y que supera la clásica dicotomía de lo sagrado y profano.

La clase obrera, los pampinos, el pueblo entre otras etiquetas, contenía las más diversas de las expresiones. Dentro de la misma existía además una élite. La dirigencia del movimiento obrero, pensemos en figuras como Osvaldo López, Luis Emilio Recabarren o Elías Laferte pertenecían a un sector que no era el de los más pobres, ni muchos menos. Además habían tenido acceso a la educación ${ }^{4}$. El pueblo iletrado, sin embargo, era la mayoría: no sabía leer ni escribir. La dirigencia de los bailes religiosos y de los clubes deportivos -no todos- también pertenecían a este mismo estamento. Y, aun así, en su interior destacaba la figura del dirigente o del caporal, que por su carisma se imponía por sobre los demás.

Esta cultura popular además tuvo una fuerte interacción, no exenta de conflictos, con la llamada cultura oficial o de la élite. La presencia de esta se dejó sentir a través, por ejemplo, de la construcción de teatros como el Municipal de Iquique y el de Pisagua. También por la fundación de periódicos y por la instalación del ferrocarril. La prensa escrita significó en parte socavar la tradición oral y el ferrocarril alterar la noción de paisaje

\footnotetext{
${ }^{4}$ Sin olvidar además que los que se ocupan de la cultura popular son profesionales que componen un objeto de estudio de acuerdo a las categorías del saber mandatados por el saber ilustrado (de Certeau 60).
} 
Artículo. Bernardo Guerrero. "Chuzos, lápices y matracas, proletarios, poetas y promesantes en el norte grande de Chile"

y de distancia. La poesía obrera por cierto mantiene un aire de la tradición oral, aunque solamente se expresa en la prensa. No sabemos si es qué y cómo se declamó y bajo cuáles formas $^{5}$. La poesía obrera circuló solamente en el restringido campo de la prensa popular. Careció de otras formas de difusión como ser publicada en libros, y con ello salir del espacio regional donde se producía. El ideario de la elite fue replicado por la clase obrera, que fundó ateneos obreros y periódicos, en una especie de contrabalance.

\section{Chuzos, lápices y matracas}

Chuzos, lápices y matracas simbolizan al proletariado en tres de sus tantas ocupaciones en la pampa salitrera. El chuzo, la herramienta con la que de sol a sol el pampino extraía el caliche del duro suelo. El lápiz junto al papel, en el que este obrero se rebelaba contra las injusticias y las deplorables condiciones laborales, además de construir un proyecto liberador que era el socialismo. La matraca ${ }^{6}$, el instrumento musical con que a través de los bailes religiosos en forma organizada se ofrendaban en cuerpo y alma a la virgen del Carmen. Lápices y matracas se expresaban en la noche, luego de la jornada de trabajo. Es el tiempo de la noche, lo contrario al tiempo del trabajo. Un tiempo cualitativamente diferente y superior. Las noches y sus proyectos era lo único que les pertenecía. La poesía obrera se inscribe, sin embargo, en el paradigma de la Ilustración, la razón como instrumento preponderante para el encuentro de la verdad, mientras que la religiosidad popular se ubica dentro de un paradigma pre moderno. Ambos tienen diversas concepciones acerca del tiempo y del espacio.

En este trabajo desarrollo las conexiones entre esos tres elementos. La lectura de poesías obreras, el análisis de los cantos religiosos me permite elaborar algunas conjeturas, acerca de algunas ideas que vienen inspirada del texto de Rancière, La Noche de los proletarios. Se complementa además con algunas ideas de Leccardi (2014) sobre la concepción del tiempo en la modernidad. Discuto cómo en el universo de los proletarios del salitre coexisten, con contradicciones en algunos casos, diversas percepciones y formas de considerar el tiempo.

\footnotetext{
${ }^{5}$ El único antecedente que tenemos del teatro de esa época fue ver actuar y escuchar declamar a Willie Cegara, veterano actor de teatro en Iquique (1908-2005).

${ }^{6}$ Hay otros instrumentos, pero usamos la matraca ya que se usa por una sola persona, que canta, baila y además ejecuta ese instrumento.
} 


\section{La pampa dura}

La pampa salitrera del Norte Grande de Chile recibió a miles de hombres mujeres y niños que, trabajando de sol a sol y en condiciones adversas, lograron domesticar "el desierto más árido del mundo". Y en este proceso de domesticación el culto a la virgen del Carmen, La Tirana, jugó y juega hasta hoy un rol fundamental. La historiografía clásica nacional por lo general olvida el rol cumplido por la religiosidad popular en este proceso. La ortodoxia comunista y anarquista construyó un obrero ilustrado y ateo, fiel al modelo de la ilustración europea de los siglos XVIII y XIX.

Los obreros junto con luchar por mejores condiciones de vida encontraron en el culto a La Tirana, una forma de expresar su fe religiosa, instancias de sociabilidad, de organización independiente y en algunos casos, en contradicción con la Iglesia Católica, además de elaborar un proyecto de vida colectivo, con un sentido de vida.

En este artículo entregamos algunas ideas para valorar el rol de la religiosidad popular en la construcción de la cultura popular nortina.

\section{Abránse las calles...}

La explotación del salitre en el Norte Grande de Chile significó, entre otras consideraciones, la concentración de una gran cantidad de población, de hombres y mujeres venidos de diversas partes del mundo en busca de mejores condiciones de vida. Al decir de Bahamonde (1978), aventureros, que vieron en el salitre una nueva California:

Los hombres llegaron a estos lugares atraídos por una llamarada fascinante: la plata de Chañarcillo, la plata de Caracoles, la plata de Huantajaya, el cobre de Chuquicamata, el esplendor del salitre y sus posibilidades de vida fácil, el auge de los puertos, el cosmopolitismo de sus bahías. Avalanchas humanas acudieron a estas tierras. Y la otra impresión que produce la zona es la aventura. Todos llegaron aquí movidos por el incentivo aventurero; el negocio fácil, el trabajo rendidor, el contrabando, el golpe de suerte, etc. Sin embargo, mirado el problema del poblamiento nortino con más calma, resulta distinto. Se trata de un lento proceso de integración; integración del hombre a esta tierra $\mathrm{y}$, además, integración de la tierra a la economía nacional (Bahamonde, Notas 13). 
Artículo. Bernardo Guerrero. "Chuzos, lápices y matracas, proletarios, poetas y promesantes en el norte grande de Chile"

Habitaron y ayudaron a construir la ciudad y sobre todo la extensa pampa salitrera en el desierto de Atacama. Se calcula que en la región de Tarapacá funcionaron cerca de 166 oficinas salitreras y campamentos. Unas más grandes que otras, concentraron una sociabilidad obrera y salitrera ${ }^{7}$ de la que en la actualidad aún quedan huellas, como las oficinas de Humberstone y Santa Laura, que en el año 2005 fueron declaradas Patrimonio de la Humanidad por la Unesco.

Lugar de trabajo y de esparcimiento, las oficinas salitreras se convirtieron en el territorio donde el naciente proletariado se las ingenió para vivir o mejor dicho para sobrevivir. Trabajó por el día y por la noche se organizó para planificar actividades deportivas, coordinarse para ir a La Tirana o bien para asistir a reuniones de carácter político y culturales como el teatro obrero.

Parafraseando a Rancière (2010), la noche de los proletarios pampinos consistía en realizar sus deseos. El día era para el agobiante trabajo. Al caer el sol, la sociabilidad obrera se daba mañas para efectuar lo opuesto al trabajo. No era por cierto un trabajo que los "realizara" como personas. El tiempo del día, de las duras jornadas de trabajo, era un tiempo perdido. La noche era la única oportunidad que tenían para satisfacerse como personas, o bien para pensar en sus vidas más allá de las contingencias del trabajo asalariado y mal pagado. El tiempo de los proletarios, según Rancière, es el tiempo fragmentado, tiempo de la dominación (9). Pero en las noches proletarias, no sólo hay espacio para cultivar el saber por la poesía, lo hay también para la fiesta, la diversión y para los bailes religiosos.

El tiempo de los patrones, tiempo de la modernidad, administrado por el reloj de sol a sol, no era el tiempo de la realización personal. Por la noche, otro tiempo asomaba, aquel en que se cultivaba la esperanza de un mundo mejor. El tiempo de la noche, parecía ser el tiempo de la fiesta. En la noche, al decir de Certeau, se hace la fiesta (Certeau 44). En la noche se encuentran los proletarios, en el día se pierden en sus duras jornadas. El tiempo de la poesía y el tiempo de los bailes religiosos, es el tiempo de dar rienda suelta a su vocación.

\footnotetext{
${ }^{7}$ Así se les decía a los patrones y dueños de las oficinas salitreras.
} 


\section{Trabajar y danzar: el tiempo y el espacio de los proletarios}

Los obreros del salitre se movían en dos tiempos. El del trabajo y el de la danza. El primero en el día, el segundo en la noche. El tiempo del trabajo ha sido denunciado en sus deplorables condiciones, no sólo de trabajo, sino que también ambientales. El poeta Víctor Domingo Silva escribe:

Yo he visto, en el bochorno de aridez de la pampa al roto, pecho abierto junto a la abierta pampa, hendir el vientre enorme de esa opulenta tierra que llenó de cadáveres otro tiempo de guerra hendir aquella tierra, prodiga de tesoros y arrancarle el salitre que vale más el oro. La Nueva Marsellesa (Víctor Domingo Silva, citado por Cobos 50)

Con respecto a la mujer se lee en el siguiente poema:

Las pálidas mujeres de la pampa envejecen de anemia y de clorosis... I la que el Vicio en su avidez no zampa se le engulle la cruel Tuberculosis. Fragmento de La pampa de Chile de Alejandro Escobar y Carvallo (Bravo-Elizondo y Guerrero Historia 53).

Y se describe la Oficina Salitrera:

¡A lo lejos parece la Oficina un hormiguero de labor constante. $\mathrm{Y}$ un campamento gris, de calamina... un bocado en el vientre de un gigante! ¿Queda en pié la infernal explotación donde pena el obrero noche y día... Donde el parásito voraz: "patrón"... sus tentáculos vé en la Pulpería!... ¡Y el calichero que la sangre suda, la realidad de Prometo encarna... sobre la Pampa bajo el Sol desnuda, como una piel comida por la sarna! Fragmento de La pampa de Chile de Alejandro Escobar y Carvallo (Bravo-Elizondo y Guerrero Historia 55). 
Artículo. Bernardo Guerrero. "Chuzos, lápices y matracas, proletarios, poetas y promesantes en el norte grande de Chile"

El poeta escribe en el año 1909, impactado aun por la matanza del 21 de diciembre de 1907. Por cierto, las condiciones de trabajo cambiaron, pero no mucho. No significa que los pampinos/proletarios/mestizos, hayan vivido mejor. Hasta los años 70, por ejemplo, en la oficina Victoria y Alianza las casas carecían de alcantarillado.

Las fuentes que nos informan sobre la situación de pobreza de los pampinos son amplias: poesía, canciones, novelas y los registros históricos en que se da cuenta de problemas de alcoholismo, salud mental, prostitución, etc. (Salas, Comisión). Pero nada o muy poco se nos dice acerca del mundo de la religiosidad popular en la pampa salitrera. Las pocas notas que existen se las debemos a la prensa de la época y a la llamada novela del salitre. Pero ambas, a pesar de su distancia política, se unen en base al paradigma ilustrado desde donde observan e interpretan ${ }^{8}$.

Esta cita de la novela Caliche de Luis González Zenteno lo grafica así:

El pasado volvía a ocupar su lugar con toda la fuerza de su tradición. Resucitaba la fe supersticiosa del hombre primitivo que creía en brujos y maleficios y se ponía cubierto de los mágicos poderes con plumas, collares, máscaras, pieles, guairuros, piedra imán y otras fruslerías (González 123).

O bien esta nota con carácter paternalista acerca de la fiesta:

Impresiona dulcemente el alma ver la devoción y de nuestro pueblo sencillo y bueno, tan manso y creyente en la paz como fuerte y valeroso en la guerra. En estos días el trabajador de la pampa deja su pala y su barreta para dedicarse al culto de la virjen santísima, con esa fe ardiente que los hace invencibles cuando se trata de defender el honor de su patria y los hace paciente y resignados cuando se trata de sufrir en la lucha por la vida. Con pueblos como el nuestro me sentiría con el valor de Juana de Arco para guiarlo por el camino de la victoria en medio del estruendo atronador de la batalla (Mariana, La Patria, julio de 1912).

"Pacientes y resignados, fuertes y valerosos en la guerra" son las expresiones que usa la articulista para referirse a estos hombres y mujeres. Pero no hay más. "Fe ardiente" para resumir lo que es el culto a la virgen del Carmen. Los obreros del salitre poco o nada

\footnotetext{
${ }^{8}$ Tanto la prensa obrera como la de derecha concuerdan en describir en términos ilustrados la realidad de la pampa (Guerrero, La Tirana. Así).
} 
dejaron escrito. Las pocas referencias están en la poesía popular que escribieron en los periódicos y que afortunadamente ha sido compilada en libros (Pérez, Poesía; González, Illanes y Moulián, Poemario).

Es el tiempo de la noche en que los obreros, por lo general poco alfabetizados, nos dejan constancia de sus motivaciones a través de la escritura. El registro escritural sólo alcanza para estampar en el estandarte el nombre del baile, la fecha de su fundación y su lugar de pertenencia. Aunque es dable suponer que la confección de los mismos no debe ser más antigua que la de los años 30. Las que sí deben ser más antiguos son las libretas de cantos a la virgen. Piezas anónimas, cantadas en forma colectiva en las festividades religiosas populares. Por ejemplo:
A tu presencia divina
dentraron tus morenitos
escucha a tus devotos
tus Morenos de Victoria.

Morenos se refiere a los bailes de origen afrodescendientes y expresa la existencia de este grupo étnico de esclavos en la yunga boliviana. La Tirana y sus bailes es la expresión de una multiculturalidad puesta en escena por los obreros del salitre (Guerrero Religiosidad). Por otro lado, para la ortodoxia marxista y anarquista, el obrero es un sujeto universal cuya acción social está regida por la razón. El hombre autónomo, soberano liberado del peso de la tradición y de las costumbres, es el ideal.

Los obreros agrupados en los bailes religiosos construyen un discurso de la diversidad. Por lo mismo, sus trajes, coreografías y cantos son el modo que tienen de registrar la experiencia de lo sagrado mediante la ritualidad del bailar y del cantar.

El espíritu ilustrado de la época penetra fuertemente en las conciencias de la elite proletaria. Pero no se trata, en el caso de la religión, de un ateísmo, sino de un anticlericalismo. Ejemplos hay muchos, pero baste este:

El credo de Jesús, con desenfado, hoy sus Ministros lo interpretan mal; él fue pobre y murió crucificado, predicando el amor, la libertad Fragmento de La verdadera religión 
Artículo. Bernardo Guerrero. “Chuzos, lápices y matracas, proletarios, poetas y promesantes en el norte grande de Chile"

Blanco, ecuatoriano.

El Pueblo, octubre 5, 1899.

(González, Illanes y Moulián 65)

No se reniega de Cristo, al contrario, se le alaba en cuanto hombre que se sacrificó por la humanidad. La poesía obrera, como ya se dijo, tiene un fuerte carácter anti-clerical. Se vincula a los curas con los salitreros. Este poema así lo describe:

Por fin, señor Editor, esta no es primera vez que el enemigo burgués intenta contra su honor.

Hoy con venganza y vigor

Cárter le sale al camino, como canalla e indigno, ha querido echarlo a tierra;

pera para darle guerra cuenta con el sagasquino

Fragmento de Versos Pampinos

Sagasquino. Oficina California.

El Pueblo, agosto 6, 1903

(González, Illanes y Moulián 222).

En los dos libros que compilan poesía obrera del Norte Grande de Chile en la época salitrera, no se hace mención a la fiesta de La Tirana. No se nombra y ningún poeta la ataca ni la ridiculiza. Está, eso sí, invisibilizada. ¿Silencio cómplice? Me inclinaría a que sí.

En la obra de Luis Advis, "Cantata Santa María de Iquique", en la que narra la matanza del 21 de diciembre de 1907, un obrero viejo, a través del sueño, anuncia la tragedia que vendrá:
Por el mar
por el mar aparecerá,
yo soy viejo
y sé que vendrá...

Se refiere a los marinos que desde Valparaíso vinieron a reprimir a los obreros del salitre. La actividad onírica y sus mensajes tienen un gran protagonismo en la cultura 
popular, sobre todo en la andina y campesina que a través de los enganchados poblaron el Norte Grande (Guerrero, Nunca).

La noche de los peregrinos/pampinos es una noche de creatividad y de ensayos. Reunidos en las calles de las oficinas, acompañados de instrumentos de viento y de percusión, presididos por la imagen de la virgen del Carmen, llamada en tono familiar Chinita, preparan el viaje al pueblo de La Tirana. En cada oficina salitrera pasa lo mismo. Tanto el clero como los salitreros observan con cautela esta manifestación que no alcanzan a comprender.

La fiesta de La Tirana fue, hasta los años 70, solventada y organizada por los mismos peregrinos. Un esfuerzo de auto-gestión y auto-producción religiosa. Los cantos, las danzas, los trajes, los estandartes, la confección de las imágenes, responden a esa economía simbólica auto sustentada en la devoción a la Carmen/Chinita.

Esta devoción permitió además romper la idea moderna y occidental del territorio, tiempo y espacio que la percibe como algo homogéneo y vacío (Leccardi). Para los peregrinos el lugar donde se emplaza el santuario no es sólo pampa; es pampa sagrada a la que hay que acceder de un modo respetuoso. Es un bello paisaje: lo habita la virgen. Además, la belleza de la virgen lo inunda todo:

Eres madre poderosa refulgente como estrella la más pura y la más bella doy toda alabanza, la más santa y milagrosa.

Morenos de San Lorenzo

Esta religiosidad popular mariana, además con su estrategia de desconocer los límites entre lo público y lo privado, sacraliza el hogar, la sede social, incluso su cuerpo, por el artificio de instalar allí, en esos espacios, la imagen de la virgen o del santo. Sacralizan los espacios cotidianos (Guerrero, Religiosidad). Se resignifica un territorio que para el salitrero es sólo objeto de riqueza, y para los obreros, explotación, en el lugar de la comunión con la Virgen:

Salga el lucero brillante con su claridad y primor vengan todas las estrellas alumbrado en este día. 
Artículo. Bernardo Guerrero. “Chuzos, lápices y matracas, proletarios, poetas y promesantes en el norte grande de Chile"

Hay además una concepción del tiempo que no es lineal, como el tiempo del trabajo. Un tiempo que se administra en dos, antes y después del 16 de julio. Un tiempo cíclico que nos recuerda el tiempo primordial en la que las cosas fueron fundadas. Por ejemplo:

Los Gitanos de Antofagasta

llorando ya se despiden

volveremos para el año

si tú nos prestas la vida.

Volver para el año es la idea, que grafica una concepción no moderna del tiempo:

Que tristes momentos

en que ya nos vamos

danos vida para el año

para que todos volvamos.

La religiosidad popular resignifica el territorio. El desierto, la pampa, así le denominan los pampinos, no es desierto. No puede ser, ya que en él la virgen produce milagros.

\section{Cantos y poesía}

El origen de los cantos religiosos de los santuarios del Norte Grande, "constituyen una herencia cultural muy antigua y una creación religioso-cultural, típicamente colectiva" (Van Kessel 7). Lo anterior señala una antigüedad que no es posible de precisar. Las libretas de cantos que cada peregrino posee no indican año. El estandarte nos remite a la fecha de fundación de la cofradía, pero acerca de los cantos no hay nada. Sin embargo, podemos afirmar que datan del tiempo de la Colonia.

Los cantos religiosos forman parte de un circuito mayor y se pueden clasificar en cantos de entrada, saludos del alba, aurora, saludos (buenas tardes, buenas noches), procesión y retirada.

Estos cantos tienen formas básicas. Se componen de una serie de estrofas con cuatro versos. Poseen un ritmo métrico y una rima. 
Las estrofas son intercaladas por un estribillo que responde a las pautas anteriores y que se canta con la misma melodía. Las estrofas se cantan a capella, pero el estribillo es acompañado por la banda musical (Van Kessel 36).

El caporal juega el rol de administrador del ritual. Este mismo autor dice que los cantos son "una creación literario-religiosa de carácter colectivo, uno de los pocos casos que observamos hoy en Chile (Van Kessel 36).

Los cantos, además, se construyen y expresan desde un colectivo:

Desde lejos llegamos

para estar junto a ti

virgen de La Tirana

soberana todos juntos hoy

te veneramos danos tu bendición.

El yo se disuelve en el nosotros. Se trata de una ética social en la que el grupo se impone sobre el individuo. El pasado cercano a esta actitud parece estar en la cosmovisión andina, en que la comunidad se impone por sobre los intereses personales.

La poesía obrera se ubica por cierto en la categoría de la modernidad, sobre todo en lo que respecta a la presencia de un autor. Los poemas nacen en la época del salitre y tienen un autor que escribe, ya sea con nombres y apellidos, o bien con un pseudónimo.

Para González, Illanes y Moulián, la poesía obrera se inscribe como "una forma de pensamiento definido básicamente como poético. Un pensamiento en que la reflexión crítica respecto del yo y del mundo, no sólo se manifiesta como razón analítica, sino principalmente como razón poética, propia quizás de una fase pre-racionalista de la sociedad" (González, Illanes y Moulián 13).

Esta autora hace un análisis por estilo de esta producción, señala en primer lugar a la décima glosada, siendo el maestro, a seguir Bernardino Guajardo, poeta santiaguino. Este verso es de ese estilo:

Desgraciado, desgraciado es sin duda el proletario, que aquí viene entusiasmado y sucumbe en el Calvario. Del poema Rachas Amargas. 
Un pampino. El Pueblo, mayo 13, 1902 en:

(González, Illanes y Moulián 162).

Están también los poetas con una formación intelectual, al servicio del pueblo. Se trata entonces de un corpus muy heterogéneo en la discursividad poética, pero tiene en común denunciar las miserables condiciones de trabajo. Por ejemplo:

En el periodismo la verdad es la espada de lo valientes, como la mentira es el arma de los cobardes.

Al escribir para el público se necesita tres cosas; valor, dignidad y talento.

Francisco A Loayza

El Pueblo, marzo 13, 1906

(González, Illanes y Moulián 359).

Creación colectiva y creación individual, poesía religiosa y poesía combativa, son los ejes de estas producciones. Ambos géneros reflexionan sobre el territorio que habitan. Sus autores, el pueblo, que viven en condiciones miserables, se expresan mediante estas piezas literarias. El siguiente cuadro lo sintetiza:

\begin{tabular}{|l|l|l|}
\hline \multicolumn{1}{|c|}{ Categorías } & \multicolumn{1}{c|}{ Canciones } & \multicolumn{1}{c|}{ Poemas } \\
\hline Autor & No existe, es colectivo & Individual \\
\hline Registro & Oral & Escrito \\
\hline Ámbito & Local & Local \\
\hline Dimensiones & Religioso & Político \\
\hline Voces & Popular & Popular \\
\hline
\end{tabular}

Sin embargo, la poesía popular a diferencia de los cantos religiosos de La Tirana, está prácticamente desaparecida. No hay quien la sustente y menos que la produzca. No sucede lo mismo con los cantos religiosos de los santuarios del Norte Grande que gozan de una envidiable buena salud. Acevedo Hernández (2015) anunciaba el fin de esta actividad que, para el caso del Norte Grande de Chile, se cumple. Sin embargo, adquieren relevancia los autores de canciones que tienen como tema la religiosidad popular. Es el caso de Manuel Veas y Toño Miranda autores de "La Reina del Tamarugal", de Patricio Flores con 
"Rocío de la Pampa" y de Osvaldo Torres Espinosa con sus canciones dedicadas a san Lorenzo, además de Arturo Barahona, Tesoro Humano Vivo.

\section{Conclusiones}

Un mismo territorio, pero percibido de un modo distinto. Árido, terrible, engañoso, de allí el fenómeno de los empampados ${ }^{9}$. Objeto de explotación, de injusticias y de sueños frustrados. Todo ello registrado en diversos dispositivos como la crónica, la novela, el teatro y, sobre todo, la poesía. A través de estos registros queda en evidencia que la noche de los pampinos buscaba la construcción de un nuevo día, el del socialismo.

Pero también estos obreros ocuparon la noche para edificar el culto colectivo a la virgen del desierto, de la pampa del Tamarugal. Era una religiosidad no de la palabra sino del culto (Morandé, Ritual), centrada en el cuerpo que busca ser colectivo. El baile religioso viene a ser el nosotros que sintetiza los cuerpos individuales. De allí la expresión cuerpos de baile, que los viejos bailes aún poseen.

Durante el día el pampino posee un cuerpo que trabaja para otros. Un cuerpo que le es extraño, no le pertenece en el sentido de la economía política de Marx.

En la noche, un cuerpo que baila y canta para la virgen que protege y perdona. Un cuerpo que se auto-lacera para conseguir el perdón de sus pecados. No es el cuerpo sacrificado el 21 de diciembre de 1907 en Iquique o en La Coruña, o el 5 de junio del año 1925. Son cuerpos de hombres y mujeres que, representando a otros, tal vez más explotados, (pieles rojas, gitanos, morenos, etc.) construyen el sueño de la búsqueda del perdón, de trabajo digno y de salud.

Sin embargo, la poesía está escrita por obreros, está elaborada por hombres y con firma de autor. ¿Qué significa esto? No hay lugar para la escritura de las mujeres en este registro. El ocupar el espacio de lo privado, de lo cotidiano, al parecer las hace carecer de un régimen escritural. Tal vez en las cartas podamos encontrar algo de sus demandas, deseos, etc. Y la firma del autor se inscribe en la tendencia de la modernidad de producir un autor dotado de su propia subjetividad. No pasa lo mismo en los cantos religiosos que son y

\footnotetext{
${ }^{9}$ Se le dice a aquel que, al internarse por la pampa, pierde el sentido de la orientación. "Se empampó" es la expresión que designa a aquel que nunca más regresó. Ver por ejemplo el cuento de Ferraro (1979) y la crónica de Mouat (2001).
} 
Artículo. Bernardo Guerrero. "Chuzos, lápices y matracas, proletarios, poetas y promesantes en el norte grande de Chile"

siguen siendo piezas colectivas, o al menos sin firma de autor. Es una herencia de larga data.

La noche de los proletarios, la de los poetas, sin embargo, terminó. El golpe de Estado del año 1973, el capitalismo neoliberal y sus procesos de individualización, la crisis de los partidos políticos, entre otros factores, convirtieron la noche, ya no en un tiempo de sueños utópicos, sino que, en un lugar de descanso, para reponer la fuerza de trabajo para el día siguiente. La así llamada poesía popular o poesía obrera es cosa del pasado. Hay chuzos, pero no lápiz y papel.

La noche de los peregrinos ha continuado. Sin embargo, como consecuencia del golpe de Estado de 1973, debieron los peregrinos refugiarse en la Iglesia Católica. Pero el costo que debieron pagar fue la pérdida de su autonomía: la auto-producción religiosa debe pasar ahora por el control del aparato eclesiástico. Es cada vez menos mariana la fiesta y más cristocéntrica. Las matracas siguen sonando, pero ya no como el único sonido de la fiesta. Los altoparlantes por los que se transmiten las misas, a menudo, silencian el sonido de los instrumentos tradicionales.

\section{REFERENCIAS}

Acevedo Hernández, Antonio. Los cantores populares chilenos. Ediciones Tácitas, 2015. Bahamonde, Mario. Pampinos y salitreros. Ediciones Quimantú, 1973.

Bahamonde, Mario Notas sobre el desarrollo de la literatura nortina. Editorial Universitaria, 1978.

Burke, Peter. La cultura popular en la Europa moderna. Alianza Universidad, 1991.

Bravo-Elizondo, Pedro. Cultura y teatro obrero en Chile. 1900-1930. Ediciones Michay S.A., 1986.

Bravo-Elizondo, Pedro y Bernardo Guerrero. Historia y ficción literaria sobre el Ciclo Salitrero en Chile. Ediciones Campvs-Universidad Arturo Prat, 2000.

Certeau, Michel de. La cultura en plural. Nueva Visión, 2009.

Cobos, Julián. "Yo vi nacer y morir los pueblos salitreros". Nosotros los chilenos. Ediciones Quimantú, 1971.

Ferraro, Nicolás. Tomás Godoy, el empampado y otras historias del Salar Grande. Editorial Nascimento, 1979.

Guerrero, Bernardo. "Tarapacá, la novela maldita". A 90 años de los sucesos de la Escuela Santa María de Iquique, edición de Artaza y González. Dibam, Lom, Centro de Investigaciones Diego Barros Arana-Universidad Arturo Prat, 1998, pp. 139-152

Guerrero, Bernardo. Nunca la flor creció. Centenario de la Matanza en la Escuela Santa María. Ediciones El Jote Errante, 2007.

Guerrero, Bernardo. "Religiosidad popular y vida cotidiana en el Norte Grande de Chile". Cuadernos de Teología, vol. VII, núm. 2, diciembre de 2015, pp. 158-177 
Guerrero, Bernardo. La Tirana. Así pasen los años. 1891-1973. Fundación Crear, 2019.

González, Sergio, María Angélica Illanes y Luis Moulián, recopiladores. Poemario popular de Tarapacá 1899-1910. Dibam-Universidad Arturo Prat-Centro de Investigaciones Barros Arana, 1998.

Pérez, Alejandro. Poesía desprotegida. Compilación de poesías de periódicos antofagastinos de 1900 a 1920. Dirección de Extensión Académica y Cultural Universidad Arturo Prat, 1996.

Mouat, Francisco. El empampado Riquelme. Libros del Náufrago, 2001.

Morandé, Pedro. Ritual y palabra. Aproximaciones a la religiosidad popular latinoamericana. Instituto de Estudios de la Sociedad, 2010.

Moretic, Yerko. El Relato en la Pampa Salitrera. Ediciones del Litoral, 1962.

Leccardi, Carmen. Sociologías del tiempo. Ediciones Universidad Finis Terrae, 2014.

Ranciére, Jacques. La noche de los proletarios. Archivos del sueño obrero. Tinta Limón Ediciones, 2010.

Sagan, Francoise. Buenos días tristeza. Tusquets Editores. Barcelona, 2015

Salas, Manuel. Comisión Consultiva del Norte. Imprenta Cervantes, 1908.

Salinas, Maximiliano, Daniel Palma, Christina Báez y Mariana Donoso. El que ríe último... Caricaturas y poesías en la prensa humorística chilena del siglo XIX. Editorial Universitaria-Corporación de Patrimonio Cultural de Chile y Centro de Investigaciones Diego Barros Arana, 2001.

Sapiro, Gisele. La sociología de la literatura. Fondo de Cultura Económica México. D.F., 2016.

Spivak, Gayatri Chakravorty. ¿Puede hablar un subalterno? El cuenco de plata, 2011.

Van Kessel, Juan. El desierto canta a María. Bailes Chinos de los Santuarios Marianos del Norte Grande, Serie La Fe de un Pueblo, Tomo I. Ediciones Mundo, 1971. 